LETTER TO THE EDITOR

\title{
Methodological insight for assessment of haemodynamic perfusion in neural retina and optic nerve
}

\author{
Indicazioni metodologiche per la valutazione della perfusione emodinamica della retina \\ neurale e del nervo ottico
}

\author{
Alessandro Martini' ${ }^{1}$ Flavia Sorrentino ${ }^{2}$, Francesco Parmeggiani ${ }^{3}$ \\ ${ }^{1}$ Padova University Research Center "I-APPROVE - International Auditory Processing Project in Venice "Santi Giovanni e Paolo" \\ Hospital, Venice, Italy; ${ }^{2}$ Otorhinolaryngology, Department of Neuroscience, University of Padova, Padova, Italy; ${ }^{3}$ Department of \\ Translational Medicine and for Romagna, University of Ferrara, Ferrara, Italy
}

KEY WORDS: BPPV, retinal haemodynamics, OCTA

PAROLE CHIAVE: BPPV, emodinamica retinica, OCTA

Dear Editor,

We read with great interest the article by Neri and co-workers focusing on the evaluation of vascular factors in patients with recurrent benign paroxysmal positional vertigo (BPPV) ${ }^{1}$. By study design, the vascular factor was specifically assessed using both extracranial colour-coded duplex sonography of vertebral arteries (ECCSVA) to examine vertebral flow, and retinal fluorangiography (FAG) to indirectly study the cerebral microcirculation. In the above-described diagnostic methodological context, the authors affirm that "The FAG excluded qualitative alterations of the cerebral microcirculation" ", but this conclusive statement appears to be supported only by an outdated speculative presupposition of FAG-based correlation between retinal and cerebral haemodynamics ${ }^{2}$, which has lost its investigative value soon after the introduction of diagnostic tools specifically aimed at the measurement of retinal microvascular blood flow, such as scanning laser Doppler flowmetry ${ }^{3}$ and, above all, optical coherence tomography angiography (OCTA) ${ }^{4,5}$. During the last years, OCTA has been repeatedly applied for quantitative assessment of retinal haemodynamics, detailing that microvascular changes in the retina can reflect small vessel cerebral changes in patients with Alzheimer's disease or cognitive decline ${ }^{4,6-9}$. In this current scenario, OCTA definitely represents the first-choice method to verify the contribution of vascular factors in a clinical manifestation such as BPPV, and its unexpected non-utilisation is probably as result of a lack of updated scientific literature search in absence of an ophthalmologist within the authors' research group. In fact, during the indirect evaluation of cerebral microcirculation, OCTA allows very higher levels of specificity and sensitivity compared with FAG, also avoiding the risks related to the intravenous injection of fluorescein, the vital colourant used to carry out FAG. In view of that, among BPPV patients reported by Neri and co-workers it is not possible to exclude alterations of cerebral microcirculation which could be indirectly highlighted by a safe and modern methodological approach using several important OCTA-based outcome measures, such as peripapillary and parafoveal perfusion densities of
Received: May 19, 2021

Accepted: June 14, 2021

\section{Correspondence}

Alessandro Martini

Padova University Research Center "I-APPROVE International Auditory Processing Project in Venice

"Santi Giovanni e Paolo" Hospital, Venice, Italy via N. Giustiniani 2 (sede amministrativa), 35128 Padova, Italy

Tel. +39049 821 6369/8997. Fax +39049821 1300

E-mail: alessandromartini@unipd.it

Funding

None.

Conflict of interest

The Authors declare no conflict of interest.

How to cite this article: Martini A, Sorrentino F, Parmeggiani F. Methodological insight for assessment of haemodynamic perfusion in neural retina and optic nerve. Acta Otorhinolaryngol Ital 2021;41:487-488. https://doi. org/10.14639/0392-100X-N1708

(C) Società Italiana di Otorinolaringoiatria e Chirurgia Cervico-Facciale

\section{c) $($ ) $९$}

This is an open access article distributed in accordance with the CC-BY-NC-ND (Creative Commons Attribution-NonCommercial-NoDerivatives 4.0 International) license. The article can be used by giving appropriate credit and mentioning the license, but only for non-commercial purposes and only in the original version. For further information: https:// creativecommons.org/licenses/by-nc-nd/4.0/deed.en 
both retinal vascular networks, choriocapillaris and choroid. Moreover, the paper does not include a complete audiological evaluation of patients: history of hearing loss and tinnitus should be investigated for a more complete assessment of the patients examined. Episodes of sudden or rapidly progressive hearing loss may be suggestive of vertebrobasilar insufficiency and many audiological disorders such as presbycusis, noise-induced hearing loss and tinnitus are suspected of being related to alterations in blood flow ${ }^{10}$. Detecting these symptoms could corroborate the hypothesis proposed by Neri at al. that ischaemic events contribute to aetiopathogenesis of BPPV. To this end, we suggest that pure tone audiometry results, THI (Tinnitus Handicap Inventory) and relevant episodes of audiological history should be collected and included in the data analysis.

\section{References}

1 Neri G, Filograna Pignatelli GR, et al. Recurring paroxysmal positional vertigo: evaluation of the vascular factor. Acta Otorhinolaryngol Ital 2021;41:77-83. https://doi.org/10.14639/0392-100x-n0502

2 Menchini U,D'Ettorre M, Mondelli M, et al. The use of retinal fluoroangiography techniques in the study of cerebral circulation. Cephalalgia 1985;Suppl 2:59-63. https://doi.org/10.1177/03331024850050S210

3 Wei X, Balne PK, Meissner KE, et al. Assessment of flow dynamics in retinal and choroidal microcirculation. Surv Ophthalmol 2018;63:646-664. https://doi.org/10.1016/j.survophthal.2018.03.003
4 Lee JY, Kim JP, Jang H, et al. Optical coherence tomography angiography as a potential screening tool for cerebral small vessel diseases. Alzheimers Res Ther 2020;12:73. https://doi.org/10.1186/ s13195-020-00638-x

5 Sardone R, Sborgia G, Niro A, et al. Retinal vascular density on optical coherence tomography angiography and age-related central and peripheral hearing loss in a Southern Italian older population. J Gerontol A Biol Sci Med Sci 2020 Oct 17;glaa269. https://doi. org/10.1093/gerona/glaa269

6 Bulut M, Kurtuluş F, Gözkaya O, et al. Evaluation of optical coherence tomography angiographic findings in Alzheimer's type dementia. Br J Ophthalmol 2018;102:233-237. https://doi.org/10.1136/ bjophthalmol-2017-310476

7 Querques G, Borrelli E, Sacconi R, et al. Functional and morphological changes of the retinal vessels in Alzheimer's disease and mild cognitive impairment. Sci Rep 2019;9:63. https://doi.org/10.1038/ s41598-018-37271-6

8 Criscuolo C, Cennamo G, Montorio D, et al. Assessment of retinal vascular network in amnestic mild cognitive impairment by optical coherence tomography angiography. PLoS One 2020;15:e233975. https://doi.org/10.1371/journal.pone.0233975

9 Gupta VB, Chitranshi N, den Haan J, et al. Retinal changes in Alzheimer's disease-integrated prospects of imaging, functional and molecular advances. Prog Retin Eye Res 2020:100899. https://doi. org/10.1016/j.preteyeres.2020.100899

10 Seidman MD, Quirk WS, Shirwany NA. Mechanisms of alterations in the microcirculation of the cochlea. Ann NY Acad Sci 1999;884:226232. https://doi.org/10.1111/j.1749-6632.1999.tb08644.x 